\title{
Forest disturbance analysis with Landsat-8 OLI data related to a parametric wind field: A case study for Typhoon Rammasun (201409)
}

\author{
Chenyan.Tan ${ }^{1,2}$, Weihua.Fang ${ }^{1,2, *}$ \\ ${ }^{1}$ Key Laboratory of Environmental Change and Natural Disaster, Ministry of Education, Beijing Normal University, Beijing 100875 , \\ China \\ ${ }^{2}$ Faculty of Geographical Science, Academy of Disaster Reduction and Emergency Management, Beijing Normal University, \\ Beijing 100875, China - weihua.fang@bnu.edu.cn
}

\section{Commission III/IVa}

KEY WORDS: Typhoon Rammasun, Forest disturbance, Wind field, Remote sensing index

\begin{abstract}
:
Forest disturbance induced by tropical cyclone often has significant and profound effects on the structure and function of forest ecosystem. Detection and analysis of post-disaster forest disturbance based on remote sensing technology has been widely applied. At present, it is necessary to conduct further quantitative analysis of the magnitude of forest disturbance with the intensity of typhoon. In this study, taking the case of super typhoon Rammasun (201409), we analysed the sensitivity of four common used remote sensing indices and explored the relationship between remote sensing index and corresponding wind speeds based on pre-and post- Landsat-8 OLI (Operational Land Imager) images and a parameterized wind field model. The results proved that NBR is the most sensitive index for the detection of forest disturbance induced by Typhoon Rammasun and the variation of NBR has a significant linear dependence relation with the simulated 3-second gust wind speed.
\end{abstract}

\section{INTRODUCTION}

As a major part of terrestrial ecosystem, forest frequently suffers from dual influences of natural disasters and human activities and has dynamic changes at all time. Tropical cyclone (TC), as one of the most powerful and destructive meteorological disasters in the world, causes damage to forest structure, function and composition in the affected area and eventually affects terrestrial carbon cycle, vegetation phenology and biodiversity $(\mathrm{Xi}, 2015)$. High wind is one of the main hazards of TC, often causes extensive damage to the trees (e.g., breakage and uprooting) and brings about great property loss to forestry. Hence, detecting the forest disturbance and evaluating the loss caused by typhoon are of great significance for deeply understanding the dynamic changes of forest ecosystems and having sustainable management, conservation and development of forestry.

The remote sensing image has been an important data source for forest multi-disaster loss assessment due to its advantages such as wide coverage and dynamic real-time monitoring. Using multispectral, relatively high space-time resolution and cloudless remote sensing images, it is able to rapidly obtain the satisfactory and reliable results of magnitude and extent of affected forest based on the specific vegetation index (Rossi et al., 2013). Currently, researches of forest disaster based on remote sensing data are limited to the quantitative detection of visual phenomena or the comparative analysis of vegetation indexes with environmental factors such as elevation, slope and aspect (Wang and Zhou, 2013; Guo et al., 2014). However, the relationship between variations of vegetation index and intensity of hazards is rarely mentioned. Although some progress has been made in several studies that the different wind speed interval durations (Ramsey et al., 2001) and the distance away from the centre of hurricane (Ayala - Silva and Twumasi, 2004) have good correlations with the variations of NDVI, there exists plenty of room to study the relationship of hazard and exposure based on the remote sensing technology and hazard analysis method.

The objective of this study is to explore whether there is a correlation between typhoon wind field distribution and magnitude of forest disturbance. A super typhoon named Rammasun in 2014 is taken as an example to perform the analysis.

\section{DATA AND METHOD}

\subsection{Study area}

As the main body of Hainan province, Hainan Island $\left(108.6^{\circ} \sim\right.$ $\left.111.3^{\circ} \mathrm{E}, 18.1^{\circ} \sim 20.2^{\circ} \mathrm{N}\right)$ is located in the southern end of China (Figure 1), covering more than 34 thousand square kilometres, and it ranks behind only the largest island Taiwan in China. Hainan Island is surrounded by coastal plains with high mountains in the central region, showing a clear ladder-like distribution. Since the island is in the tropics and surrounded by the sea, and it has the characteristic of tropical monsoon climate and tropical marine climate with high temperature and strong rain throughout the whole year. Hainan Island is one of the areas most vulnerable to typhoon generated over the western North Pacific (WNP) in history. Statistics show that a total of 153 TCs had made landfall on Hainan Island from 1949 to 2017 based on the historical best track dataset (Ying et al., 2014).

* Corresponding author 

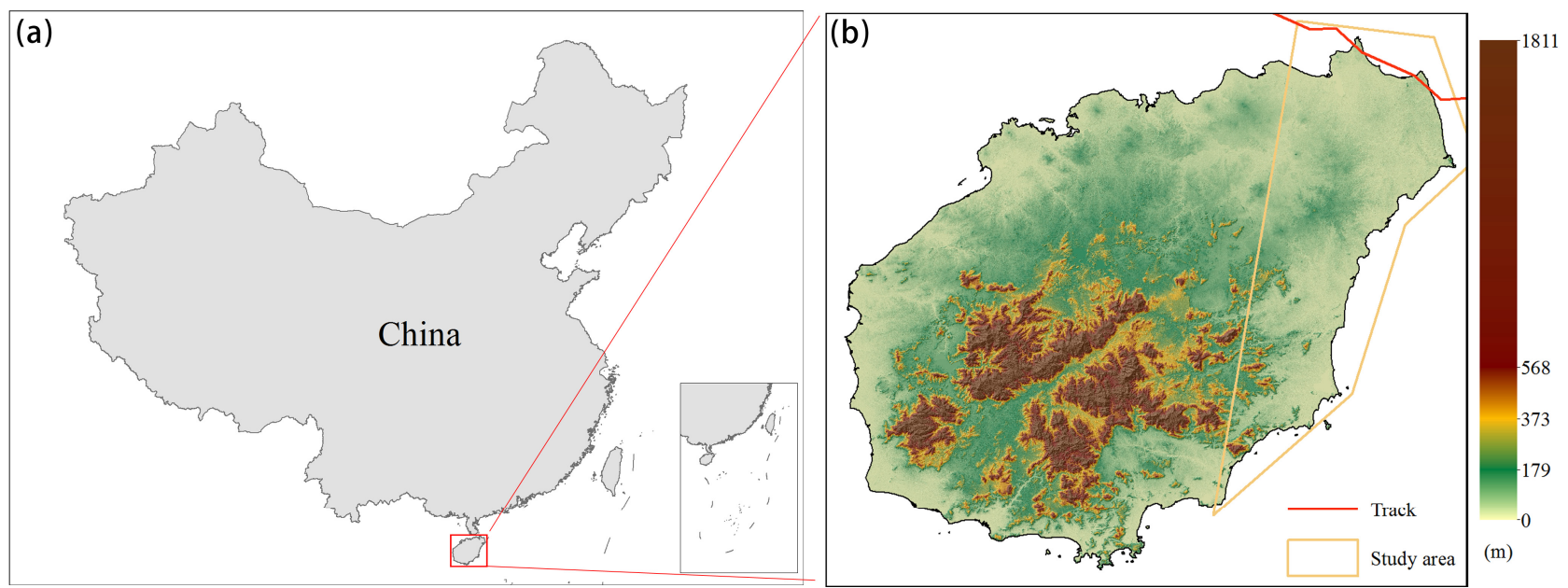

Figure 1 . Location (a) and elevation (b) of Hainan Island

On July 18, 2014, Rammasun (International identification number: 201409), one of the strongest typhoons in the WNP ever recorded, made landfall on Hainan Island. The maximum wind speed (MWS) near typhoon centre reached $60 \mathrm{~m} / \mathrm{s}$ at the time of landing, which made Rammasun become the strongest tropical cyclone landing in southern China since 1973. Multiple hazards such as high winds, heavy precipitation and strong storm surges brought by Typhoon Rammasun resulted in serious casualties and huge property losses in all affected countries, including China, the Philippines and Vietnam. Rammasun also caused severe deforestation in the affected areas, for example, survey results showed that the loss of living wood growing stock was 4.763 million $\mathrm{m}^{3}$ and the economic loss exceeded 1.3 billion Chinese Yuan in the landfall Wenchang city alone (Xue et al., 2015). Figure 2 shows the rubber tree damage taken on August 3, 2014 on Hainan Island.

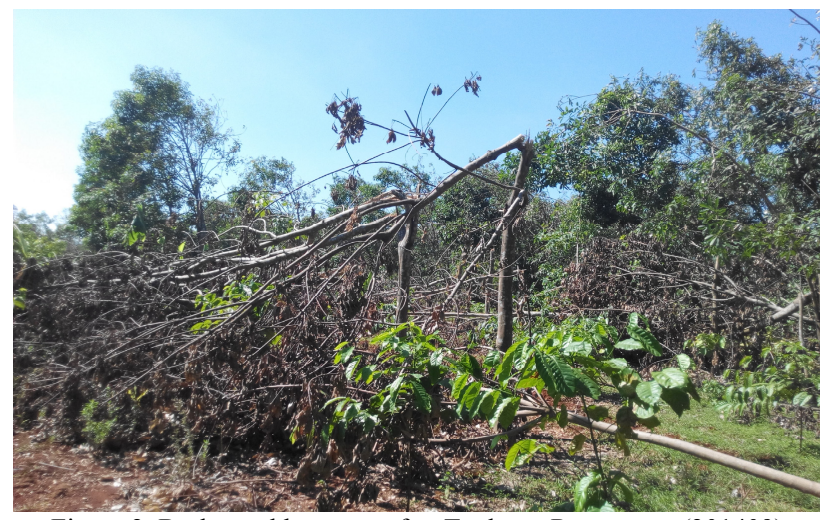

Figure 2. Broken rubber trees after Typhoon Rammasun (201409)

Due to the extensive cloud contamination, there were limited remote sensing observation data before and after Typhoon Rammasun. Here, based on the screened Landsat- 8 OLI images, we take the northeast part of Hainan Island as the study area, which is marked as yellow box and shown in Fig 1 (b).

\subsection{Data}

The track and intensity data of Rammasun were gathered from the China Meteorological Administration (CMA) (Ying et al., 2014) (Figure 3). The forest distribution data of Hainan Island was derived from the 2010 GlobeLand30 (Chen et al., 2015). Landsat-8 OLI multi-spectral images (Path/Row 123/046 and $123 / 047)$ were used in this study for the detection of forest disturbance induced by Typhoon Rammasun in Hainan Island. Although many areas were covered by clouds seen from the remote images nearly everyday in Hainan Island, however, for the accurate analysis, image acquisition time is the first thing that should be considered. After a careful comparison, four scenes of standard Level-2 terrain-corrected Landsat-8 OLI surface reflectance product from July 2nd, 2014 and August 3rd, 2014 were selected as the pre- and post-typhoon images and were obtained from the United States Geological Survey (USGS) Earth Explorer website (http://earthexplorer.usgs.gov). After mosaicking and cropping, two Landsat- 8 multispectral images covering from band 1 to band 7 were obtained for subsequent calculation and analysis (Figure 4).

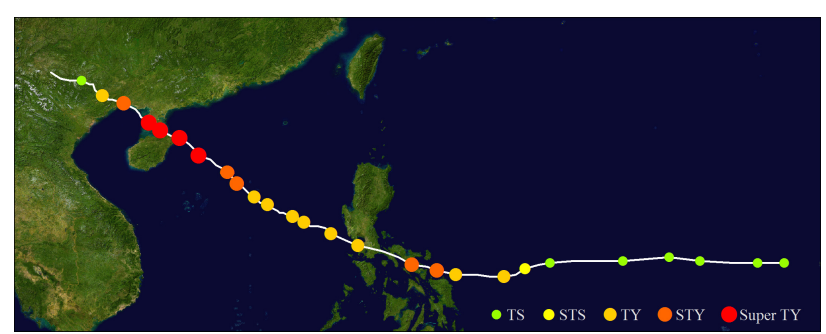

Figure 3. The track-intensity map of Typhoon Rammasun (201409)

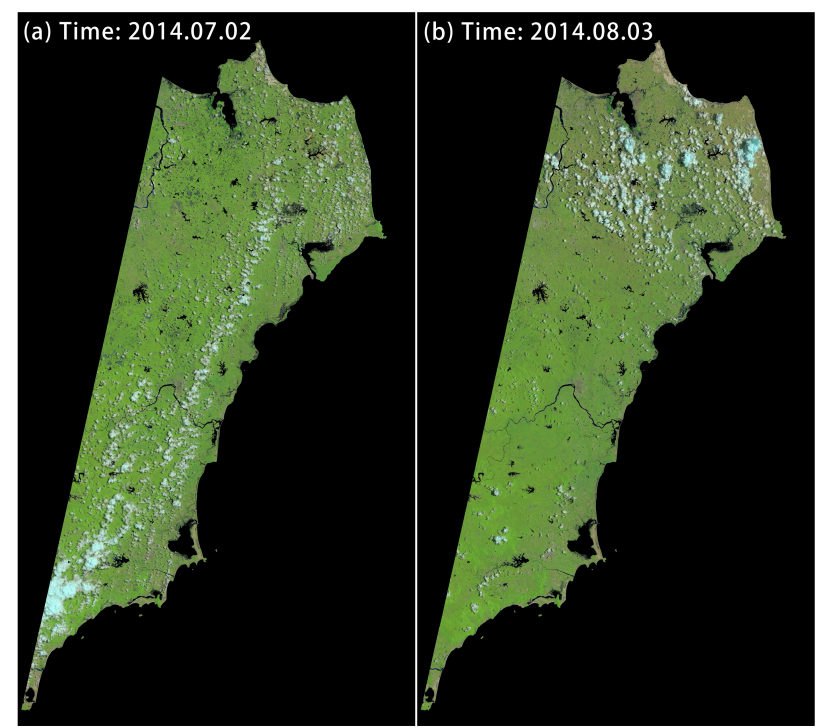

Figure 4. Natural color-image mosaics of study area before and after Typhoon Rammasun 


\subsection{Method}

Remote sensing detection method. In this study, the univariate image differencing (UID) method was carried to quantify magnitude and extent of forest disturbance induced by Rammasun. The method can be expressed as:

$$
\Delta I=\text { Pre }_{I}-\text { Post }_{I}
$$

Where $I$ is the remote sensing index, the variation $\Delta I$ represents the difference between the pre-disaster $\operatorname{Pre}_{I}$ and the post-disaster Post $_{I}$.

Remote sensing indices. Four commonly used normalized remote sensing indices were used for the detection of forest disturbance, they are normalized differential vegetation index (NDVI) (Rouse, 1973; Rouse et al., 1974), enhanced vegetation index (EVI) (Liu and Huete, 1995), normalized differential moisture index (NDMI) (Wilson amd Sader, 2002), and normalized burn ratio (NBR) (Key and Benson 1999), which can be expressed mathematically as follows:

$$
\begin{gathered}
N D V I=\frac{N I R-R \mathrm{e} d}{N I R+R \mathrm{e} d} \\
E V I=G \times \frac{N I R-R \mathrm{e} d}{N I R+C_{1} \times R \mathrm{e} d-C_{2} \times B l u e+L} \\
N D M I=\frac{N I R-S W I R 1}{N I R+S W I R 1} \\
N B R=\frac{N I R-S W I R 2}{N I R+S W I R 2}
\end{gathered}
$$

where NIR, Red, SWIR1 and SWIR2 are the reflectance values of near infrared band (B5), red band (B4), short wave infrared band 1 (B6) and short wave infrared band 2 (B7), and $C_{l}=6$, $C_{2}=7.5, L=1, G=2.5$.

Wind field model. A complete parametric TC wind field model usually consists of two components: a gradient wind field model and a planetary boundary layer (PBL) model (FEMA, 2012). In this study, the gradient wind field model derivated from Georgiou et al. (1983) and the PBL model developed by Meng et al. (1997) were combined for simulating the wind field of Typhoon Rammasun. By considering the local factors such as topographic effects and surface roughness, the parametric wind field model can produce a fairly good simulation result when compared with actual wind observations. Detailed wind field calculation process were presented in Tan and Fang (2018).

\section{RESULTS AND ANALYSIS}

\subsection{Spectral change characteristics}

According to the location information of typhoon, spectral changes of damaged forest sampling area in Wenchang city before and after Rammasun were drawn and shown in Figure 5. After Typhoon Rammasun, the surface reflectance of damaged forest for all seven bands of Landsat-8 had obvious changes. The surface reflectance in near infrared band (B5) reduced while others raised. In particular, reflectance of B5 had the maximum variation, the second and the third were B6 and B7 respectively. In visible bands, variation was the most obvious in red band (B4) while the least in coastal band (B1).

It can be predicted from Figure 5 that remote sensing indices based on short wave infrared bands probably better than the common used vegetation indices based on the red band for the detection of forest disturbance induced by tropical cyclones.

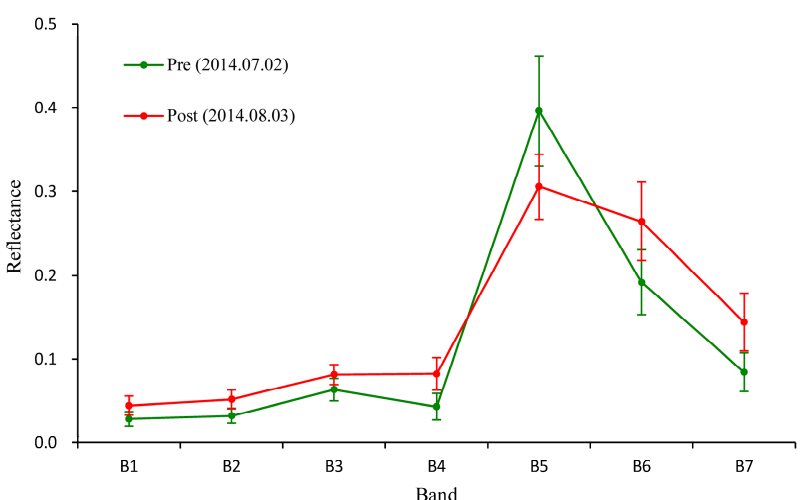

Figure 5. The characteristics of different bands of Landsat-8 pre- and post-typhoon for the affected forest sampling area (Error bars represent positive and negative one standard deviation)

\subsection{Sensitivity of remote sensing indices}

We compared image differencing histograms of the four indices for selecting the most sensitive one (Figure 6). Unaffected forest sampling areas and affected forest sampling areas were delineated by ground investigation and remote sensing visual interpretation. The difference values had been normalized using unaffected forest values based on a re-scaling method proposed by Healey et al. (2005). Table 1 shows the mean normalized variations of the four indices for the affected forest. The offset value from the unaffected forest indicates the sensitivity. The larger the offset, the higher the sensitivity.
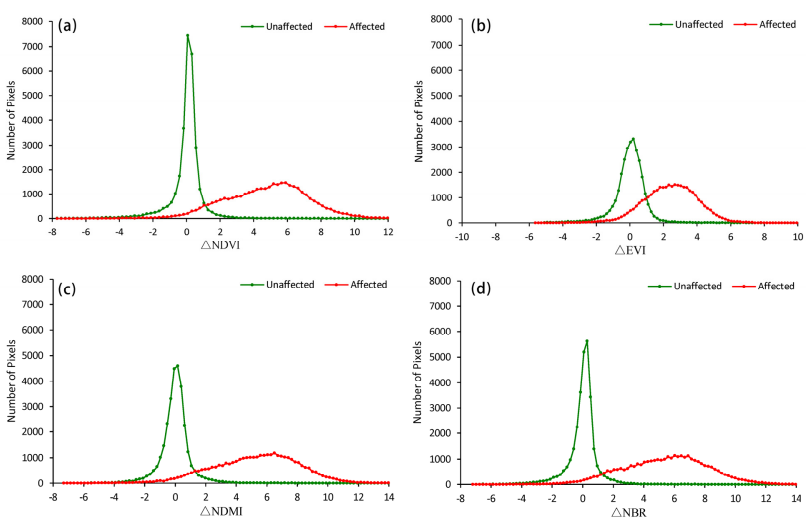

Figure 6. Normalized variation histograms of remote sensing indices

Table 1. Mean normalized variations of the affected forest

\begin{tabular}{ccccc}
\hline Index & $\Delta N D V I$ & $\Delta E V I$ & $\Delta N D M I$ & $\Delta N B R$ \\
\hline Mean & 4.7807 & 2.4221 & 5.2708 & 5.4114 \\
\hline
\end{tabular}

From Figure 6 and Table 1, we concluded that NBR and NDMI are better than NDVI and EVI for the forest disturbance detection induced by Typhoon Rammasun, and NBR is the best of the four. Hence, we used this index for the subsequent analysis.

\subsection{Wind field simulation results}

Based on the optimized parametric TC wind field model introduced in the previous section, we simulated the snapshots of Rammasun every 10 minutes and finally obtained two wind fields of 10-minute mean and 3-second gust at a resolution of one kilometre after a maximum-value composite procedure by combination of all snapshots, results are shown in Figure 7. 
(a) 10-minute mean wind field

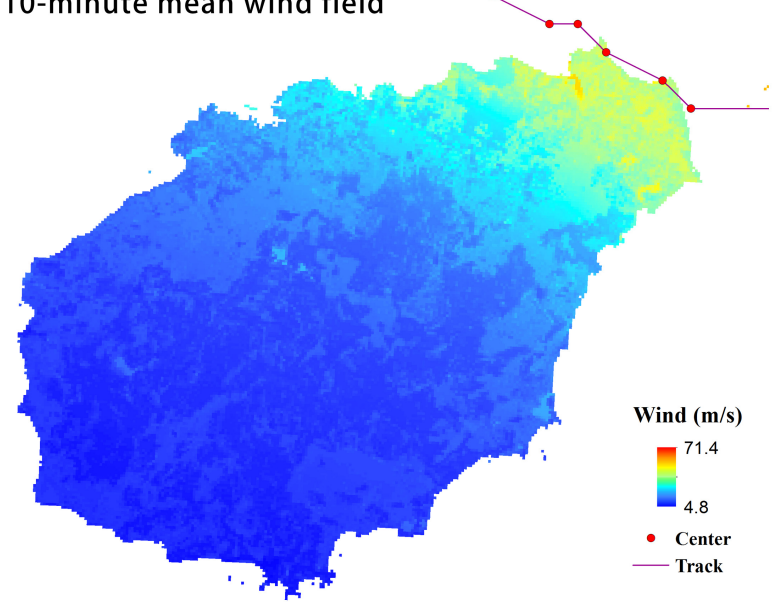

(b) 3-second gust wind field

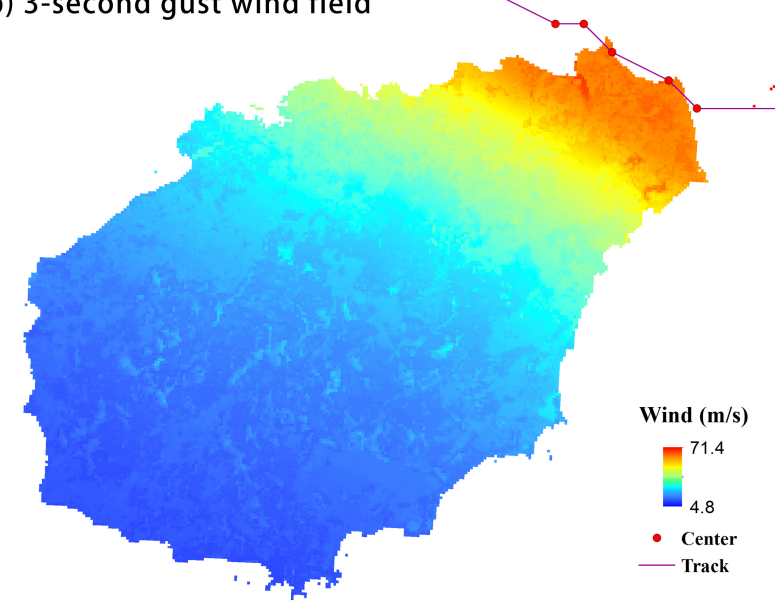

Figure 7. Simulated footprints of 10-minute mean wind (a) and 3-second gust wind (b) for Typhoon Rammasun (201409)

\subsection{Relationship of NBR and wind speed}

In order to explore the relationship between wind speed and variations of Remote sensing index, Scatter diagrams were drawn based on the simulated wind fields and NBR difference results before and after Typhoon Rammasun (Figure 8).
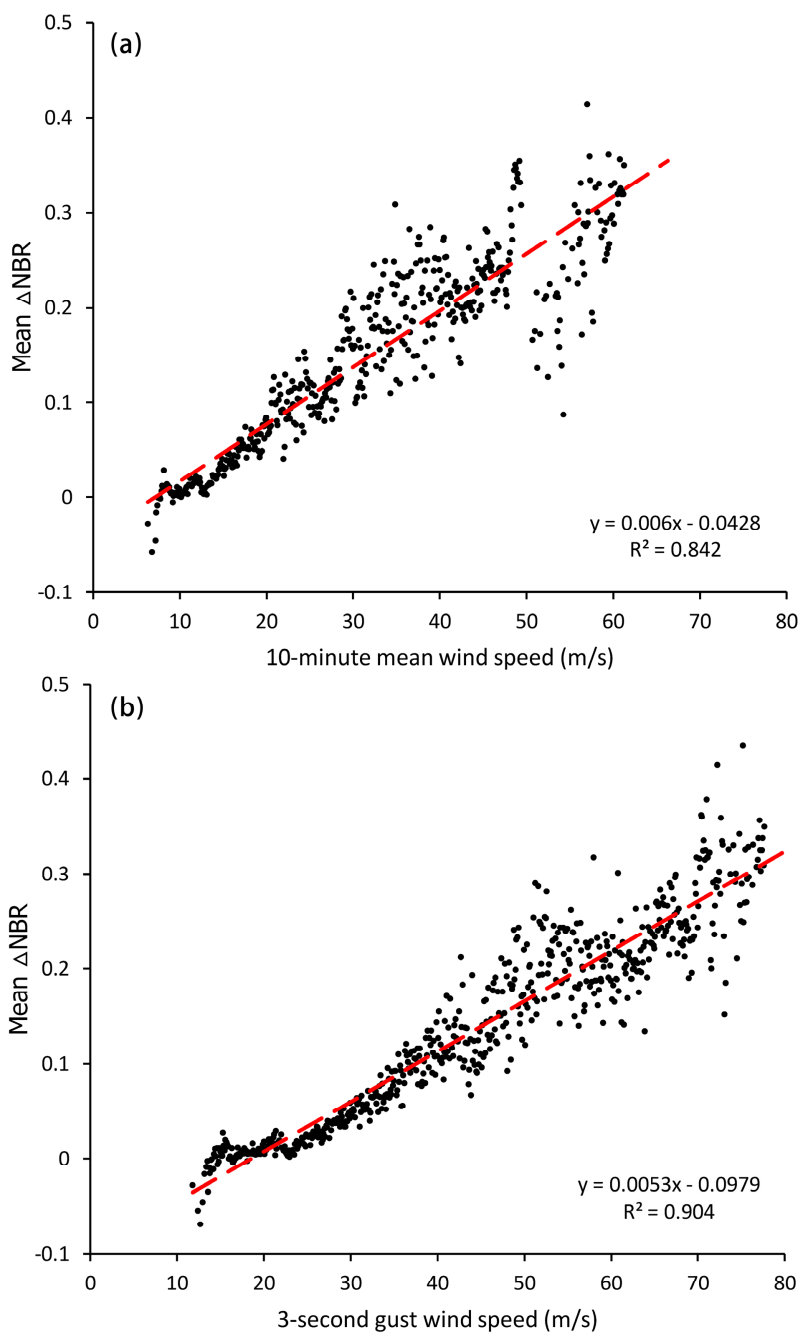

Figure 8. Scatter diagrams between mean $\triangle N B R$ and simulated wind fields of 10-minute mean (a) and 3-second gust (b)
Because of the different resolutions between modeled wind fields and $\triangle N B R$ derivated from Landsat-8 surface reflectance data, mean variations of $\triangle N B R$ corresponding to the same wind speed were calculated by zonal statistics based on wind field pixels. From Figure 8, two time intervals of simulated wind fields both have good linear correlations with $\triangle N B R$, especially for 3 -second gust wind speeds $\left(R^{2}=0.904\right)$. When the gust wind is less than $17.2 \mathrm{~m} / \mathrm{s}$, forest is barely affected with an increased NBR after typhoon. When the wind is between $17.2 \sim 24.5 \mathrm{~m} / \mathrm{s}$, NBR is reduced slightly, and then as the wind speeds up, NBR would be significantly reduced. Since high wind is one of the main hazards of typhoon, the degree of NBR change is directly related to forest damage, it can be estimated the magnitude and extent of affected forest based on the relationship established between wind and $\triangle N B R$ in Figure 8 (b).

\section{CONCLUSION AND FUTURE WORK}

In this study, we compared the sensitivity of four common used remote sensing indices based on image differencing histograms for the detection of forest disturbance induced by Typhoon Rammasun (201409) on Hainan Island and found that NBR is the most sensitive index. Then, by drawing scatter diagrams, it was found that NBR decreases linearly along with the increases of wind speed and a preferable linear fitting equation was obtained relating the simulated 3 -second gust wind field with the mean $\triangle N B R$ before and after Typhoon Rammasun.

We suspect that there exist relations among the damge loss ratio, the intensity of TC and changes in remote sensing indices. In addition, geographical environmental elements also play a key role in forest disturbance induced by TCs. All of the above factors need further exploration.

\section{ACKNOWLEDGEMENTS}

The research is supported by the National Key Research and Development Program of China (2017YFA0604903), the Key Laboratory of Environmental Change and Natural Disaster, Ministry of Education, Beijing Normal University (2015jzhz14), and the Special Fund for Climate Change of China Meteorological Administration (CCSF201719). 


\section{REFERENCES}

Ayala-Silva, T., and Twumasi, Y. A., 2004. Hurricane Georges and vegetation change in Puerto Rico using AVHRR satellite data. International Journal of Remote Sensing, 25(9): pp. 16291640 .

Chen, J., Chen, J., Liao, A., Cao, X., Chen, L., Chen, X., He, C., Han, G., Peng, S., Lu, M., Zhang, W., Tong, X., and Mills, J., 2015. Global land cover mapping at $30 \mathrm{~m}$ resolution: A POKbased operational approach. ISPRS Journal of Photogrammetry and Remote Sensing, 103(9): pp. 7-27.

FEMA (Federal Emergency Management Agency). 2012. Hazus-MH 2.1 Hurricane model technical manual. Washington, DC: Mitigation Division, Department of Homeland Security Federal Emergency Management Agency.

Georgiou, P. N., Davenport, A. G., and Vickery, B. J., 1983. Design wind speeds in regions dominated by tropical cyclones. Journal of Wind Engineering and Industrial Aerodynamics, 13(1-3): pp. 139-152.

Guo, X., Zhang, H., Wang, Y., and Clark, J., 2015. Mapping and assessing typhoon-induced forest disturbance in Changbai Mountain National Nature Reserve using time series Landsat imagery. Journal of Mountain Science, 12(2): pp. 404-416.

Healey, S. P., Cohen, W. B., Yang, Z., and Krankina, O. N., 2005. Comparison of tasseled cap-based landsat data structures for use in forest disturbance detection. Remote Sensing of Environment, 97(3): pp. 301-310.

Key, C. H., and Benson, N. C., 1999. Measuring and remote sensing of burn severity. In 'Proceedings Joint Fire Science Conference and Workshop, II', 15-17 June 1999, Boise, ID. pp. 284.

Liu, H. Q., and Huete, A., 1995. "Feedback based modification of the NDVI to minimize canopy background and atmospheric noise" IEEE Transactions on Geoscience and Remote Sensing, 33(2): pp. 457-465.

Meng, Y., Matsui, M., and Hibi, K., 1997. A numerical study of the wind field in a typhoon boundary layer. Journal of Wind Engineering and Industrial Aerodynamics, 67-68: pp. 437-448.

Ramsey, E. W., Hodgson, M. E., Sapkota, S. K., and Nelson, G. A., 2001. Forest impact estimated with NOAA AVHRR and Landsat TM data related to an empirical hurricane wind-field distribution. Remote sensing of Environment, 77(3): pp. 279292.

Rossi, E., Rogan, J., and Schneider, L., 2013. Mapping forest damage in northern Nicaragua after Hurricane Felix (2007) using MODIS enhanced vegetation index data. GIScience \& Remote Sensing, 50 (4): pp. 385-399.

Rouse, J. W., 1973. Monitoring the vernal advancement and retrogradation of natural vegetation. NASA/GSFCT Type II Report, Greenbelt, MD, USA.

Rouse, J. W., Haas, R. W., Schell, J. A., Deering, D. W., and Harlan, J. C., 1974. Monitoring the vernal advancement and retrogradation (Greenwave effect) of natural vegetatioa NASA/GSFCT Type III Final Report, Greenbelt, MD, USA.
Tan, C., and Fang, W., 2018. Mapping the Wind Hazard of Global Tropical Cyclones with Parametric Wind Field Models by Considering the Effects of Local Factors, International Journal of Disaster Risk Science, 9(1): pp. 86-99.

Xi, W., 2015. Synergistic effects of tropical cyclones on forest ecosystems: a global synthesis. Journal of Forestry Research, 26(1): pp. 1-21

Xue, Y., Yang, Z., Chen, Y., Wang, X., Wu, S., Huang, G., and Lin, Z., 2014. Typhoon 'rammasun' impact on forest ecosystem in hainan. Tropical Forestry, 42(4): pp. 34-38.

Wang, X., and Zhou, B., 2013. Assessment of the Forest Damage by Typhoon Saomai using Remote Sensing and GIS. Nature, Environment and Pollution Technology, 12(1): pp. 121124.

Wilson, E. H., and Sader, S. A., 2002. Detection of forest harvest type using multiple dates of Landsat TM imagery. Remote Sensing of Environment, 80(3), pp: 385-396

Ying, M., Zhang, W., Yu, H., Lu, X., Feng, J., Fan, Y., Zhu, Y., and Chen, D., 2014. An Overview of the China Meteorological Administration Tropical Cyclone Database. Journal of Atmospheric \& Oceanic Technology, 31(2): pp. 287-301. 